the midtarsal and subastragaloid joints because the foot was in such a bad position.

A great many patients upon whom this open operation has been carried out have returned to me months or even three or four years afterwards with a relapsed and rigid foot. In some few instances one or more manipulations, followed by suitable boots and exercises, seem to have restored the position, but in many resort to a bone operation has been necessary to deal with the deformity.

Another thing noticed in the late results of this operation is that the foot very often is much thicker in the midtarsus, and also there is a tendency for a persistent equinus to remain. This does not seem to cause any disability, but it gives the foot a rather ugly appearance. On the whole I think some feet can be improved by this method, but it appears to be very difficult to be in any way certain which cases will be permanently successful.

What has been found at operation upon those feet that have relapsed subsequent to an open correction? The midtarsal and subastragaloid joints were full of fibrous tissue binding the opposing surfaces of the bones together. This fibrous tissue was so firm that it had to be dissected away before the articular surfaces could be identified. It was quite obvious that subsequent to an open correction there must have been little if any movement in the joints. And clinical examination of feet upon which this operation has been performed has demonstrated that there is scarcely any movement. They are always rather stiff feet.

Repeatedly I have found that the scaphoid and os calcis, which at the time of the open operation had been restored to a satisfactory position so far as one could see, had returned to their original relation with the astragalus - the scaphoid on the inner side of the head and the os calcis tilted beneath it.

\section{Bone Operations}

I still believe that when all other methods of treatment have failed an arthrodesis of the subastragaloid and midtarsal joints, removing at the same time sufficient bone at these joints to produce a correction, is the best and most lasting method of treatment. It is an operation which gives a very satisfactory foot in a talipes equino-varus the result of an infantile paralysis, and it is the rational operation to perform in the deformity we are considering. I would even go so far as to say that if there is any doubt about doing an open correction an arthrodesis is probably the better line of treatment. Astragalectomy and other piecemeal bone operations should still be condemned.

To conclude, with regard to the vexed question as to whether there is or is not any inward rotation of the tibia I still hold that the real fault is a failure to correct the deformity of the foot, and that osteotomy is simply the production of one deformity to hide the existence of another.

Issued as a special supplement to The Countrywoman of August, 1937, is a report prepared by the Associated Country Women of the World on midwifery services in rural areas throughout the world (30, Baker Street, London, W.1, price $3 \mathrm{~d}$.). In a brief discussion of the report Dr. Esther Carling compares the state of affairs in America, where in New York State, for example, only 2 per cent. of deliveries take place outside hospitals, with that in France and other European countries, where the avowed policy is to make it safe and possible to have all babies born in their own homes. A mass of information is compressed into relatively short space in this publication.

\section{INSTINCT AND HYSTERIA*}

\author{
BY
}

\section{PROFESSOR ERNST KRETSCHMER}

Director, Psychiatric and Neurological Clinic, Marburg University

The study of mental diseases is not only interesting in itself, as a means of helping the patient medically, but is also of scientific importance in that it opens up the most important avenue to a knowledge of the biology of the healthy man and to an understanding of the nexus between psychological and physical phenomena. Typical psychic mechanisms appear in psychopathology in exaggerated relief and can help in the solution of general biological problems. In the same way the thorough study of general biological laws assists in the more profound understanding of psychic symptoms. Thus, formerly we studied how far hypnoid conditions in hysteria might be compared to the phenomena of the so-called "animal hypnosis." In particular we have compared the motor patterns. of hysterical tremors, attacks, stupors, and paralyses to the mechanisms of instinct, the flight and defence reactions which in the animal we call violent motor reactions and the sham-death reflex.

\section{Relation of Hysteria to Animal Instincts}

The view that certain hysterical reaction types are in close relationship to animal instincts in general is especially confirmed by the large mass of those types of reaction which centre round the impulsive life. Hysteria originates especially from two main sources: (a) the instinct of self-preservation-in the form of fear and anxiety in relation to dangerous situations-and $(b)$ from all the emotions and conflicts associated with the sexual life. Wishes, struggles, and disappointments of an erotic nature form the main group of experiences which produce hysteria in ordinary civil life, especially in women. The shock neuroses provide another very large group of hysterical reactions-not, however, in the sense that acute fright syndromes, for example, are merely identical with the hysterical neuroses which develop from the frightening experience or from chronic anxiety, but in the sense that both have a close relation to, and dissolve into, each other.

No agreement as yet has been fully reached on the question of the relation between hysteria and the fright neuroses. Even though the acute fright reactions have often been simply labelled as hysteria in consequence of their unmistakable resemblance thereto, nevertheless a sharp boundary line was drawn between them so long as the fright neuroses were only considered as acute, automatic, evanescent, and spontaneously resolved affective reactions; whereas hysteria, on the contrary, was only spoken of when such acute reactions became secondarily fixed through the purposeful intervention of a "will to sickness," a "gain from sickness." That these difficulties are not due to deficient observation on either one side or the other, but arise from the nature of the problem itself, will soon be apparent.

\section{Reactions to Fright and Danger}

What reactions do we observe as a direct result of situations which produce fright and danger? The subjects are shaken, tremulous, irritable, and confused ; they

\footnotetext{
* One of three lectures given at the Tavistock Clinic in April.
} 
mostly complain of physical symptoms-headache, insomnia, misery, palpitation, fatigability, dyspnoea on walking, and excessive reactions to damp and heat. They often exhibit great temperature oscillations and abnormal eruptions, and have exciting and very vivid dreams. An absolutely reliable and ordinary type of man is entirely altered-he is now tremulous, irascible, excited, incapable of concentration, exhibits dyspnoea on walking, palpitation, insomnia and headache, and pyrexia after such exertion as mountain climbing. The patients admit often feeling well, then again they will complain of headache, which is possibly present seeing that at such times they have bloodshot somewhat bulging eyes and a secretion of tears. During such phases they have pyrexia and a pulse rate of 100 or 120 .

Similarly Bonhöffer describes the vasomotor symptomcomplex as the most characteristic effect of fright. As belonging to the acute psychogenic effects of fright Gaupp mentions severe tremors, tachycardia, hyperaesthesia, fearsome dreams, polyuria, vasomotor secretory symptoms, and delirious clouding of consciousness. Among the survivors of the Messina earthquake in 1908 Stierlin chiefly found insomnia, increased reflexes, and rapid and fluctuating pulse.

We might say, therefore, that disturbance of the vegetative nervous system, with vasomotor manifestations prominent, is the most common feature of fright syndrome. And the resultant general instability of physical and psychic functions offers a favourable soil for the development of various types of hysteria, although only a minority of subjects will become hysterical ; in the majority spontaneous recovery will occur after a certain time. In these syndromes a psychic aim is not as yet demonstrable; they are to be considered as purely reflex.

When in those special fright syndromes psychomotor or purely psychic functions are involved, the matter of interpretation is more difficult; above all, in those pictures which resemble the "sham-death reflex" and the "violent motor reaction"-the fright stupor, the twilight states, senseless running away, tremors, and convulsive attacks. According to their external symptomatology these pictures do not differ fundamentally from the usual hysterical reactions which occur in the absence of acute shock as a result of emotional disturbance. Nevertheless we may say that the acute fright syndromes are distinguished to a certain extent from the ordinary hysterical reactions by a strong predominance of vegetative vasomotor signs, by their tendency to more primitive physical effects, convulsions and twilight states, and also to a certain degree by the pure forms of fright stupor.

Is it possible always to differentiate between the fright reactions and hysteria according to their inner psychological structure? Observations on shock psychoses of recent occurrence and of short duration in vigorous men have resulted in the following description: "It was possible on seven occasions to observe directly the awakening from the exceptional condition. The contrast between the twilight state in which the person exhibited theatrical behaviour, which in individual cases went so far as puerilism and nonsense talk, and the awakened state was quite astounding. As a rule it was difficult to realize that this now smart, self-contained, inconspicuous man was the buffoon of the twilight state. The awakening occurred suddenly."

From such observations it follows that even the acute psychic fright syndromes do not produce manifestations so automatic and physiologically limited as to "knock out" the psyche, but that they frequently contain elements which point to an active psychic participation which-therein lies the important point-exhibits a directly purposeful quality. Not only do the precipitating fright experiences often undergo repression or transformation ("The man has fallen over," says a patient in a frighttwilight-state, instead of "He has been killed"), but the fright-twilight-state, also, even in vigorous and brave persons, may in a remarkable manner assume forms we are otherwise accustomed to see in criminals and to regard as signs of crude hysterical deceptive tendencies, bordering on simulation-the Ganser syndrome with its falsely directed theatrical behaviour.

\section{Examples of Fright Reactions}

Stierlin also reports numerous examples of similar fright reactions from the earthquake catastrophes of Messina and Valparaiso. A certain incomprehensible composure or even a contrasting cheerfulness with repression of the terrifying experience was the most frequent psychological sequel of the catastrophe. In many cases, however, this tendency to repression proceeded to take the form of puerilism or of a ludicrous pseudo-dementia. "Thus, on the morning of the earthquake at 7 o'clock, a man of prominent position, who together with his family had escaped death, was seen in a nightgown sprinkling the flowers in his garden with a watering-can. Another, a merchant who had lost his house and family on the day of the calamity, was seen on the quay in his nightgown and slippers with a large herring in his hand, laughing to himself." "Another person who had lost his family in the earthquake, and had escaped with nothing more serious than shock, did not appear as though the disaster had made the slightest impression upon him. It seemed to mean nothing to him, although he saw his house in ruins and heard the catastrophe being discussed. He appeared to be delighted, and rode round in his motor car. When anyone spoke to him he was much confused, and kept on laughing. Yet in ordinary circumstances he was a good, sound family man." "After being thrown out of the window by the atmospheric pressure, a 17-year-old youth, as though by a miracle, landed uninjured on a meadow. Without showing the slightest concern for his family, he wanted to assist with rescue work, during which he played the clown. His severe confusional state lasted for more than a week. During the whole of that period he showed no kind of concern for what had happened, and never inquired about his family nor about anyone's safety. $\mathrm{He}$ seemed to know nothing about the whole event. One could see him aimlessly wandering about the streets in his shirt-sleeves." "Night after night a 65-year-old bank official ceaselessly called out 'Papa, mamma; Papa, mamma.' He imagined that his physician was a marshal, and addressed his own son as father."

It is scarcely possible to avoid the conclusion that the acute fright reactions often include from the start a tendency to flight from unbearable circumstances into a peculiar state, involving both repression and theatrical behaviour-in other words, the very psychic reactions which are nowadays usually regarded as forming the specific nucleus of hysteria. We shall more readily recognize the close relationship between fright neuroses and hysteria when we remember that both have a common biological origin-namely, the general animal instincts of defence.

\section{How Hysteria and Fright Reactions Differ}

Yet we must differentiate between hysteria and the fright reactions. Certainly acute terror (equally chronic 
anxiety arising out of acute fear) is one of the most favourable starting-points for hysterical formations. But the fright neurosis remains essentially an acute syndrome, whose features are stamped by the severe affect of the moment, and which lasts only throughout the period of affective strain. The purposive factor has not as yet achieved independent expression, but is vaguely inherent in the anxiety-affect in much the same way as the tendency of a drowning person to clutch at a straw may be regarded as belonging to his anxiety-affect. In the case of the true fright neuroses both repression and theatrical behaviour disappear automatically pari passu with the after-effects of the acute shock. The patient comes to himself as the clear, energetic person he was previously; and again takes up life at the point where he left it. Most acute fright reactions end in that way. A new factor enters into those fright and anxiety reactions which develop into chronic hysteria. With the gradual return of reflection and composure the patient enters on a transitional phase in which the residua of the acute mechanisms become influenceable by the will, inasmuch as he is able to suppress them entirely or to allow them to develop still further. This is confirmed by my own clinical experience as well as experimentally. If during the return to normal the egotistical wish for a permanent removal from the dangerzone or for material gain secures the upper hand, it may interfere with the subsidence of the affective automatisms and give rise to a fixation. He is still in a position to fall back on a relapse into an acute anxiety, or twilight, state ; the slight original tremor of predominantly autonomic origin can be reinforced so as to produce coarse tremors and shaking attacks.

Therefore, if we wish correctly to understand the relationship between hysteria and fright neurosis we must distinguish between two aims: (a) the primary aim, the primitive flight or defence tendency inherent in every strong painful affect and which forms the basis of the repressions and theatrical behaviour met with in the acute fright reactions; and (b) a secondary aim, which only makes itself felt during the subsidence of the acute affective shock and the return to normal, and which now produces a chronic hysteria out of the acute fright syndrome. It is at this stage that we can speak of hysteria proper. The acute affect, which includes the aim, dominates in the fright neurosis. In hysteria, originating from acute affect or from a chronic fear for one's life, the more lasting aim, which influences and utilizes the residua of affective mechanisms, governs the picture more and more. The former, the fright reaction, is essentially instinctive, created by a momentary, overwhelming situation. The latter, secondary hysteria, is more on the boundary between the instinctive and the rational, and, more than the former, is the product of the entire personality. That is why we are unable to separate the fright neuroses from hysteria, but also cannot identify them with each other.

\section{Physiological Refiex Mechanisms in Fright}

Is the acute fright reaction a purely physiological reflex in which the psyche as such does not participate, or does it depend, hysteria-like, on auto-suggestion? According to previous observations, we will answer this question as follows: In the acute pictures of fright physiological reflex mechanisms are just as surely demonstrable as hysterialike elaborations of experience. The autonomic-vasomotor symptom complex may serve as a characteristic example of the first type, and, psychically speaking, directly includes the disturbance of sleep as well as the affective instability anxiety and depression. Also certain twilight states with predominantly organic features, observed by Bonhöffer, and many epileptic-like convulsive attacks fall into this group. On the other hand, the twilight state of the Ganser type, with its fright-manifestations, best exemplifies the direct psychic elaboration of fright reaction with hysteria-like mechanisms. The direct acute fright syndromes represent varying combinations of these two main factors; frequently they appear inextricably mixed in the same symptom-picture.

It is of significance in considering the relationship between the instincts and the hysterical reactions to note that the "major hysterias" with their richly developed massive symptomatology-for example, reflex mechanisms, violent motor reactions, stupors, paralyses, and twilight states-are commonly associated with situations which conflict strongly with the impulsive life-that is, with the erotic instincts and with the instinct of self-preservation. In the war one saw these massive hysterias develop not only as the result of acute, dramatic fright situations, but still more frequently they developed out of gradually progressive anxiety for one's safety-for example, behind the lines or in a military hospital where there was a dread of further exposure to danger. The reverse is true of such purposive neuroses whose secondary gain is not so directly anchored in the impulsive life-for example, the compensation neuroses of civil life. These are characterized by their diffuse symptomatology, their vagueness, and by the frequent absence of reflex, hypobulic, and hyponoic mechanisms. Only where the impulsive life is closely impinged upon do we come across the primitive instinctive reactions-for example, violent motor reactions and sham-death reflexes.

\section{Hysteria and the Sexual Impulse}

Let us now consider the relationship between hysteria and the sexual impulse. One aspect of these relations was emphasized in general medicine, and still more in Freud's psycho-analysis; they were even regarded as the governing principle in the theory of hysteria. As a reaction against his over-emphasis they have at times been understated. In short, it must be admitted that there is an important nexus between hysteria and that instinct, but this relation is not invariable. The sexual impulse only comprises one-half of these relations; the other half, which is just as important, is. formed by the hysterical fright and anxiety reactions.

In the development of an individual case of hysteria combinations and anastomoses frequently occur between the sexual impulse and the fright-anxiety group. In neurosis a repressed sexual impulse often manifests itself as anxiety. On the other hand, especially in children, genuine anxiety can accompany sexual excitement. Thus we find hysterical reactions which have long been dormant in the form of an erotic psychic conflict are suddenly released by a fright-producing experience. A woman, who is getting old, enters into a severe state of inner tension and jealousy over the engagement of her younger sister; one day she is terrified in the street by a team of frightened horses, and suddenly exhibits hysterical abasia; she had never before reacted hysterically to fright. And, therefore, one impulse-stimulus can blend with another, so that combined they can produce an hysterical reaction.

Women and girls exhibit sexual hysteria more frequently than men. It would lead us too far astray if we were to give in detail all the erotic conflicts which might give rise to hysteria. Amongst the most frequent we might 
mention: an unsuccessful love affair, jealousy arising out of the marriage of a sister, an undesired marriage, fear of pregnancy, difficulties in sexual intercourse, an unhappy marriage. At one moment the physical, at another the psychic side of the sexual impulse is the more hysterogenic.

\section{Constitutional Foundations of Hysteria}

For our present thesis the constitutional foundations are more important than individual experiences. Apart from war and compensation hysterias, our observations (which concur with Kräpelin's) show that the majority of hysterias occur round about the age of puberty, and much more frequently in the female sex. As is well known, the age of puberty is the most susceptible period for the release of constitutionally determined anomalies. As a matter of fact, we find an astounding number of constitutional anomalies among our hysterical material: infantilism, which generally manifests with special strength in the field of sex. Our clinical material of the last few years is especially rich in physical asthenia, genital malformations, dysmenorrhoea; and in the psychic field, general childishness, weakness of the sexual impulse, aversion to men, an over-strong psychic fixation on the mother, a generally disturbed pubertal development with retardation, or uneven establishment of the separate manifestations of puberty. In contradistinction to the compulsion neurosis, the signs of sexual infantilism are very frequently found in the hysterias; but the cruder perversions are relatively seldom present. Homosexuality most frequently manifests as an exaggerated and erotically coloured enthusiasm for girl friends, which may again be interpreted as an increased or a prolonged phase of an essentially normal early pubertal phenomenon; it can therefore be considered as only a partial manifestation of the infantilistic disturbances of puberty.

As an example of such a disturbance of pubertal development in hysteria we may mention the following case. A 22-year-old girl, who exhibited bad temper, hysterical twitchings, and an impulse towards selfmutilation, menstruated for the first time in her seventeenth year. Even to this day she has a physical aversion to men, but experiences strong sexual excitement, which, in the manner of young pubescents, she satisfies by fantasy and masturbation. Even now her letters show a mixture of childish naïveté and pathos, a combination of the droll and tragic, characteristic of the "flapper." She said: "If I do not get well father must order my coffin at once, then it will make no difference even if I am damned. Someone may yet come for me. I am forgotten by God and the world. When someone does come, bring mademoiselle's apples to me." She had retained a childish kind of bigotry, and pestered the sensible old local parson with her incessant confessions of all her sins of thought and acts of masturbation. The clergyman well realized that she at one and the same time strove against and gratified her particular impulses in the confessional. Because the clergyman, during confession, was not strict enough with her, she had recourse to a Catholic priest, an alleged exorcist. She soon began to exhibit the usual mixture of adoration and erotism, and, influenced by his suggestions, she rapidly developed into a full-blown hysteric.

Without much difficulty we can perceive how this entire hysterical development of personality, up to the final appearance of twitchings, originated as a result of pubertal arrest, and remains indefinitely fixed in an early pubertal phase. The sexual impulse has retained its earlier structure, and, although lively and urgent, has failed to seek the normal sexual goal. The opposite sex is prudishly rejected. The impulse works itself out, on the one hand, in fantasy and dreams, and, on the other, in masturbation. Her bigotry, too, is nothing more than a tortuous channel by which the impulse finds concrete expression. The constant confessions involve an urgent and continuous preoccupation with sexual matters. After the faulty canalization of the non-adult impulse, it assumes more extravagant religious and semi-erotic forms, and finally, when the affective tension reaches a certain height, culminates in an hysterical motor discharge.

The same thing may happen to the sexually immature woman on marriage. Here also we find, as in early puberty, confused and vaguely compulsive feelings-a combination of disgust and negation with ungratified idealistic yearnings-which oscillate and do not permit of a normal love life, and finally discharge indirectly through the old hysterical instinctive channels. If vital anxiety is added to fright hysteria, then the symptom picture of the more sexually derived hysterias exhibits anger and disappointment together with erotic ecstasy, especially in the form of hysterical attacks and twilight states. There may also be irradiation into the sensory field, involving genital, quasi-genital, or symbolically displaced dysaesthesias.

Such immature women, with the sexual development of a 15-year-old girl, are suddenly faced with the realities of adulthood. That is why the approach of a concrete suitor, who was at first enthusiastically longed for in an idealistic way, or the prospect of marriage, is followed by instinctive defence-reactions, such as convulsions and sham death. Among prostitutes both syndromes-sexual infantilism and a tendency to hysterical reactions-are met with with striking frequency.

Physical infantilism, more often a deficient capacity for love, and exaggerated prudishness and shyness in themselves frequently hinder the attainment of concrete, happy love. Such girls are apt to develop into warped "otd maids." On account of their lack of amiability they readily become Cinderellas, and act the part semigenuinely with their poor affective equipment, martyr-like. "I am a neglected child, no one brings me presents, I never receive justice." She quietly puts up with everything, does not aspire to earthly goods, just requires a modest living, peace, and repose. She finally develops into a pseudo-ascetic bigot, or even exhibits a bitter, rebellious attitude of resentment, involving a permanent warping of the character. Her life is typified by constant friction with brothers, sisters, and parents, expresses itself in little malicious remarks and acts of revenge of an offensive, hysterical nature, lying in bed for weeks, or alarming attacks. Or she may exhibit a sudden dramatic collapse with symptoms of major hysteria, which may occur at a moment such as the engagement of a younger sister. Then once more the perverted impulse shows itself violently as sexual envy, and is discharged in instinctive reactions.

\section{Regression in the Hyst:ric}

Just as the impulsive life of the hysteric is often incompletely developed in ${ }^{-a}$ progressive sense, so also it often undergoes regression. Impulsive attitudes proper to childhood continue into adult life, as may often be shown in the relation to the parents. In hysterical individuals, as with many schizophrenics and schizoids, it sometimes happens that a proper resolution of the emotional attachment to the parents and the easy neutral independence of the adult are not attained. With excessive tenderness he remains clinging to his mother. The authority of the father retains its almost god-like quality, so that he 
rebels against it violently and yet cannot break away. A 19-year-old youth develops a feeling of paralysis in his arm out of fear of his strict father, who is always urging him to work. In young women one observes hysterias which are wholly directed against the father and the home environment, and attacks which represent stormy impulsive discharges of anxiety and anger against them.

These forms of hysteria constitute a link with the real hysterias of childhood, which partly arise in connexion with the relation to parents or parent-substitutes. In children the relation to the parents is comparable in strength to sexual relations between adults, and is also instinctively derived. Also the close relation of hysterical reactions to fright and anxiety holds good with children as with adults. But there is an important differencenamely, that in children the hysterical forms of expression are generally more closely related to the normal ways of affective discharge than in the case of adults, and, therefore, strong childish reactions to severe painful stimuli merge gradually into what is essentially hysterical. Consequently, in children we more often find hysterias of an episodic, meaningless character which are not rooted in strong impulsive tendencies but arise from transitory momentary affects, imitation, and so on.

Many symptoms of what is called the "hysterical character" are nothing more than the fixed residua of an early pubertal psyche or unfavourable characterological modifications of the same under the altered demands of later life-namely, the characteristic antithesis between coldness and excess of erotic feelings-that is, an overlively and over-idealistic psychosexuality with prudish rejection of the physical aspects of sex, enthusiasm for impressive persons, a preference for what is loud and lively, a theatrical pathos, a taste for brilliant roles, heroic fantasies, the playing with the idea of suicide, enthusiastic self-sacrifice, combined with a naïve, sulky, childish egotism. An immature psyche of this sort has a greater inclination towards impulsive discharges of affect, and especially towards hypobulic mechanisms. The hypobulic phenomena appear partly as circumscribed hysterical outbreaks (especially in the hysterical attack) and partly as permanent stigmata of the so-called "hysterical character" which, on account of its strongly hypobulic nature, we call capricious, in view of the distinctive contrast between stubbornness and exaggerated suggestibility shown therein.

\section{The Effervescent Type}

The effervescent type of psyche associated with early pubescence is very impressive and has been much described; but in our experience it is by no means the form most frequently given to hysterical reactions. Hysteria is more common in banal and stunted types, often exhibiting infantile stigmata, both physical and psychic, intellectually weak, annoyingly apathetic, emotionally defective, anxiously shy, fearful and excitable. They comprise the whole army of markedly psychically defective persons, the mental defectives, criminals, and prostitutes, who, not because of a specific mental structure, but simply on account of their deficiency of higher psychic mechanisms, are inclined towards primitive impulsive psychic discharges, which frequently include hysterical reactions. Further, hysterics seldom belong to what is known as the "cold-blooded type," but when they do belong to that group the hysterical reactions which they show are very rich and fully developed. This type is cruel, capricious, dishonest, thievish, completely amoral, unfeelingly egotistical, malicious, and intriguing. Many of these traits have been included in the description of the so-called "hysterical character." It is in point of fact a less common definitely degenerative type bordering on moral imbecility and the schizophrenic group. Furthermore, it is well known that the type of "congenital swindler" is very much inclined to hysterical reactions.

\section{The Age Factor}

In general one may say that puberty provides the main occasion for the exhibition of hysterical reactions and developmental retardation. The presence or persistence of early pubertal psychic stigmata most easily gives rise (in addition to the severer forms of psychic defect) to the "hysterical character"-that is, to a consistent tendency for the release of hysterical reactions. Hysteria is above all a reaction-form " of naïve, undeveloped psychic life" Kräpelin); it has its roots in the impulsive life. The nearer a person approaches an archaic psychic level or the more he regresses, the more does his hysteria take on the character of a severe pathological abnormality based on degeneration; and even then only when an extremely severe experience can be excluded. In youth hysterical reactions may betray a markedly degenerate constitution, but not necessarily so.

Why do hysterical cases become increasingly rarer with advancing age? Undoubtedly because in the course of time the slighter anomalies of pubertal development do, on the whole, become adjusted, and because, in general, many varieties of hysteria have no serious abnormal constitutional background, but appear episodically in children and the young as adventitious instinctive reactions to adverse experiences and environment. Kräpelin established this fact when he said that a large proportion of his female hysterics were country girls who, as young servants, had become transplanted into a large city and were not quite equal to the change of environment. Here again one is reminded of infusoria in a pond, which, on approaching a zone unfavourable to life, immediately exhibit "violent motor reactions."

With very severe experiences, such as war or earthquakes, not only the young, but even occasionally normal adults may show panic, hysterical reactions, or shockneurosis. Thus we may conclude with Hoche that " everyone is potentially an hysteric"; for we are all carriers of archaic patterns which are usually more or less efficiently covered by more recently acquired cultural and characterological strata.

Thus hysterical reactions are to be regarded on the one hand as being congenitally determined, and as stereotyped expressions of life, which appear under common and everyday conditions, but especially at vital crises. Hysterialike reactions are, on the other hand, also stereotyped responses of human and animal organisms to intolerable experiences, and are thus closely related to healthy psychic life.

The Industrial Welfare Society has arranged a course of three lectures to explain the far-reaching changes in factory law brought about by the new Factories Act. The lectures are being given by Mr. H. Samuels, barristerat-law, at the headquarters of the society, 14, Hobart Place, Westminster, S.W.1, from 6.30 to 7.45 p.m. on Thursdays, September 16,23, and 30. The fee for the course is $£ 11 \mathrm{~s}$. (15s. in the case of member firms). The course will be repeated in Birmingham on Wednesdays, October 6, 13, and 20, at 6.15 p.m., at the English Theatre at the University. 